\title{
$p$-hydroxybenzoic acid inhibited photosynthetic efficiency, yield and non-photochemical fluorescence quenching in Lactuca sativa
}

\author{
M. Iftikhar Hussain*, Luis González, Manuel J. Reigosa \\ Laboratory of Plant Ecophysiology, University of Vigo, Campus Lagoas-Marcosende, E- 36310 \\ Vigo, España. (Phone: 0034-986812616; Fax: 0034-986812556). Email: mih76@uvigo.es
}

\begin{abstract}
The $p$-hydroxybenzoic acid (BA) is a widespread phenolic compound often cited as allelochemical [1], released into soil by root exudates of Avena fatua [2], leaf leachates, and decomposed plant tissues of Triticum aestivum L. [3]. Because of the herbicidal potential of BA on crops [4] and weed species [5], commercially available BA was tested on photosynthetic efficiency, yield and non-photochemical fluorescence quenching in Lactuca sativa in a glass house study. The stock solution (3mM) of BA was made in Methanol: Water (20:80). Methanol was evaporated in a rotary vaporizer and stock solution was adjusted to concentration of $1.5 \mathrm{mM}$. Lettuce (Lactuca sativa $\mathrm{L}$. cv. Great Lakes California) seeds were grown in perlite culture in plastic pots, irrigated with 500 $\mathrm{ml}$ 1:1 Hoagland solution/pot, twice in a week in controlled glass house, having temperature: 18/8 ${ }^{\circ} \mathrm{C}$ (day/night) and 12/12 h (light/darkness) photoperiod and $80 \%$ relative humidity. One-monthold seedlings were treated with $1.5 \mathrm{mM}$ concentration of $\mathrm{BA}$ and chlorophyll fluorescence measurements were performed with portable, pulse-modulated instrument fluorescence monitoring system (FMS) (Hansatech, Norfolk, England) by the method of Weiss and Reigosa [6]. Total protein was quantified by using the Spectrophotometric Bradford [7] assays using commercial bovine serum albumin as standard. Allelochemical BA reduced quantum efficiency $\left(\mathrm{F}_{\mathrm{v}} / \mathrm{F}_{\mathrm{m}}\right)$ in lettuce seedlings on all days but the effect was stronger on the fifth and sixth day. Effective
\end{abstract}


quantum yield (Ф PSII) of photosystem II was significantly decreased by BA during third, fourth, fifth and sixth day. The photochemical fluorescence quenching (qP) was significantly decreased after treatment with BA and its values was 5-folds less in treated plants as compared to control. The allelochemicals HBA also significantly reduced NPQ values as compared to control during first, second, third, and fourth day. Leaf protein contents of L. sativa were significantly reduced by highest concentration of BA $(1.5 \mathrm{mM})$. Some other allelochemicals like BOA [8] were also reported to inhibit Fv/Fm ratios. These results indicate that Fv/Fm, quantum yield of PSII electron transport, and qP can be used indirectly to elucidate allelopathic influence of BA on lettuce plants.

\section{Bibliography}

[1] Reigosa, M.J., Gonzalez, L., and Souto, X.C. 1999. Effect of phenolic compounds on the germination of six weed species. Plant Growth Regulation 28: 83 -88.

[2] Pérez, F.J., and Ormeno-Nuñez, J. 1991. Root exudates of wild oats: allelopathic effect on spring wheat. Phytochemistry 30: 2009-2199.

[3] Yongqing, M.A. 2005. Allelopathic studies of common wheat (Triticum aestivum L.). Weed Biology and Management 5: 93-104.

[4] Vaughan, D., and Ord, B.G. 2006. Influence of phenolic acids on morphological changes in roots of Pisum sativum. Journal of Science of Food and Agriculture 52:289-299.

[5] Barkosky, R.R., and Einhellig, F.A. 2006. Allelopathic interference of plant-water relationships by parahydroxybenzoic acid. Botanical Bulletin of Academia Sincia 44: 53-58.

[6] Weiss, O., and Reigosa, M.J. 2001. Modulated fluorescence, pp. 173-183, in M. J. Reigosa (ed.). Handbook of Plant Ecophysiology Techniques. Kluwer Academic Publishers, Dordrecht.

[7] Bradford, M.M. 1976. A rapid sensitive method for the quantification of microgram quantities of protein utilizing the principle of protein dye binding. Annals of Biochemistry. 72:248-254.

[8] Sánchez-Moreiras, A.M., Alberto Oliveros-Bastidas, A., Reigosa, M.J. 2010. Reduced photosynthetic activity is directly correlated with BOA accumulation in lettuce leaves. Journal of Chemical Ecology 36: 205-209. 